\title{
"Endoshield": A Physical Protective Box for Pediatric Endoscopy during the COVID-19 Pandemic
}

\author{
Busara Charoenwat', Suphasarang Sirirattanakul ${ }^{2}$, Kangsadan Hangnak ${ }^{3}$ and Itsares Muikham ${ }^{4}$ \\ ${ }^{1}$ Division of Gastroenterology and Hepatology, Department of Pediatrics, Srinagarind Hospital, Faculty of Medicine, Khon Kaen \\ University, Khon Kaen, ${ }^{2}$ Department of Clinical Chemistry, Faculty of Allied Health Sciences, Chulalongkorn University, Bangkok, \\ ${ }^{3}$ Faculty of Architecture, Khon Kaen University, Khon Kaen, ${ }^{4}$ Department of Anatomy, Faculty of Science, Mahidol University, Bangkok, \\ Thailand
}

Background/Aims: The coronavirus disease (COVID)-19 pandemic presents challenges for gastrointestinal endoscopy. Although the virus is transmitted through contact and droplets, aerosol-generating procedures produce aerosols that can spread through airborne routes. Several gastrointestinal societies have released statements to protect patients and health care providers (HCPs). This study describes a barrier box that may be used as an adjunctive device in addition to personal protective equipment during endoscopies. Methods: A transparent acrylic box called "Endoshield" was created to place over patient's head and shoulders and was tested for its ease of use for the endoscopist and suitability for patient size and position.

Results: Twelve children (66.67\%, male) with a median age of 9 years (range, 2-11 years) underwent emergency or urgent endoscopy between April and June 2020 during the COVID-19 outbreak. The most common presenting symptom was life-threatening gastrointestinal bleeding (8/12, 66.67\%), while the rest had urgent symptoms (4/12, 33.33\%). The "Endoshield" was suitable for all patient positions (left lateral position: $9 / 12,75 \%$ and supine position: 3/12, 25\%). The patients and HCPs were followed up for their symptoms on day 14 , and none of them had any symptoms of concern.

Conclusions: The "Endoshield" is affordable, reusable, and suitable for both positions. Clin Endosc 2021;54:688-693

Key Words: Aerosol-generating procedures; COVID-19 pandemic; Endoshield; Pediatric endoscopy

\section{INTRODUCTION}

In December 2019, the novel coronavirus SARS-CoV-2 was extracted from the lower respiratory tract samples of several patients with pneumonia of an unknown etiology (later identified as COVID-19) in Wuhan, China. ${ }^{1}$ Since then, COVID-19 has rapidly disseminated worldwide. On March 11, 2020, the World Health Organization (WHO) declared

\footnotetext{
Received: February 21, 2021 Revised: February 27, 2021

Accepted: March 2, 2021

Correspondence: Busara Charoenwat

Division of gastroenterology and hepatology, Department of Pediatrics, Srinagarind Hospital, Faculty of Medicine, Khon Kaen University, 123 Mitrapap road, Muang Khon Kaen, Khon Kaen 40002, Thailand

Tel: +66-43-363-012, Fax: +66-43-363-013, E-mail: busarcha@kku.ac.th

ORCID: https://orcid.org/0000-0003-4892-4993
}

(c) This is an Open Access article distributed under the terms of the Creative Commons Attribution Non-Commercial License (http://creativecommons.org/ licenses/by-nc/3.0) which permits unrestricted non-commercial use, distribution, and reproduction in any medium, provided the original work is properly cited. that this outbreak was a pandemic., Although person-to-person transmission occurs mainly through direct contact and air droplets, ${ }^{4,5}$ to date, most endoscopy societies have emphasized that upper and lower gastrointestinal endoscopies are aerosol-generating procedures (AGPs) $)^{6-9}$; therefore, it is possible for airborne transmission to occur during gastrointestinal endoscopy (GIE), which will also increase the risk of COVID-19 transmission. Pediatric gastroenterologists also have a much greater risk than adult gastroenterologists. For example, pediatric endoscopy procedures usually require deep sedation and general anesthesia. ${ }^{10-16}$ Because of the breach of personal protective equipment (PPE) during the procedure, the acrylic box named "Endoshield" has been developed as an additional physical barrier tool for improving safety from the perspective of both patients and health care providers (HCPs) during AGPs. There are currently very few published reports about physical barrier boxes, such as "Endoshield", used during AGPs. The previous studies' goals were to prevent disease 
transmission during endotracheal intubation ${ }^{17,18}$ and GIE in adults. ${ }^{19,20}$ To date, no studies have evaluated the utility of the box in pediatric settings. Thus, here we report the first study addressing these points.

\section{MATERIALS AND METHODS}

The present study was a descriptive analytical study conducted between April and June 2020 and was approved by the Faculty of Medicine's ethical committee, Khon Kaen University (HE 641065). Informed consent was obtained from the participants' guardians prior to enrollment.

\section{Patient selection}

All patients under 18 years of age who underwent emergent or urgent endoscopy, classified by risk stratification ${ }^{8}$ at a tertiary referral endoscopy center, were invited to participate in the study. Due to the limitations of the confirmation test of the COVID-19 infection kit, universal testing strategies were not affordable for our country. Symptom and exposure questionnaires were applied to determine the risk assessment of probable for COVID-19 infection. The Patients were divided into low and high risk for COVID-19 infection, which translates to different modalities of infectious control (Table 1). ${ }^{7}$ The confirmation test for COVID-19 infection was allowed only in the high-risk group. After completing each procedure, the patients and HCPs were followed up via telemedicine to evaluate their symptoms at day 14 .

The endoscopy was performed under general anesthesia in all patients. They were not stable enough to undergo deep sedation due to emergent or urgent conditions, underlying diseases, or other complications. ${ }^{10-16}$

\section{"Endoshield" information}

To minimize droplets and airborne particles that could contaminate HCPs during AGPs, a transparent acrylic plastic box was placed so that it covered the patient's head and shoulders. This box, called "Endoshield", was tested to confirm its suitability and fit for all positions (left lateral position for general endoscopy procedures and supine position for endoscopic esophageal dilatation and percutaneous endoscopic gastrostomy $[\mathrm{PEG}])$. A schematic of the three dimensions and a general overview are presented in Figs. 1 and 2, respectively.

The acrylic plastic box measures $0.45 \mathrm{~m}$ (width) $\times 0.50 \mathrm{~m}$ (length) $\times 0.50 \mathrm{~m}$ (height) with a $3 \mathrm{~mm}$ wall thickness.

Recently, an acrylic box for endotracheal intubation (not described here) has been used for intubation in adults; however, it was difficult to apply to pediatric patients. Thus, only standard PPE was used in pediatric circumstances. When sedation was established by an anesthesiologist, the mouthpiece was placed on the patient's mouth, the endoscopic nurse also assisted in maintaining the patient's position, and vital signs were monitored. "Endoshield" was applied to the patient by placing it over their head and shoulders; GIE was then performed and upon completion of the procedure, the "Endoshield" was removed. Lastly, the endotracheal tube was extubated by an anesthesiologist.

After the AGPs, the "Endoshield" was washed with water, and then 70\% alcohol was applied to both the inner and outer parts for decontamination.

\section{Statistical methods}

Continuous and categorical variables are described as medians (and interquartile ranges) and frequencies (\%), respectively.

Table 1. Risk Assessment Base on Symptom and Exposure Questionnaires for Probable COVID-19 Infection in Endoscopy Patients

\begin{tabular}{ll}
\hline \multicolumn{1}{c}{ Risk assessment of probable COVID-19 infection } \\
\hline Low risk & Asymptomatic (eg, fever, respiratory symptoms, anosmia, or diarrhea) \\
& AND \\
& No contact with high-risk or confirmed COVID-19 positive person \\
& AND \\
& No travel to or residence in the high-risk area of COVID-19 during 14 days before \\
High risk & Presence of symptoms (eg, fever, respiratory symptoms, anosmia, or diarrhea) \\
& OR \\
& Travel to or residence in the high-risk area of COVID-19 during 14 days before \\
& OR \\
& Contact with high-risk or confirmed COVID-19 positive person \\
\hline
\end{tabular}

These criteria may change rapidly with time so it is essential to use the latest information.

Adopted from Chiu et al. ${ }^{6}$ and Gralnek et al. ${ }^{7}$ 


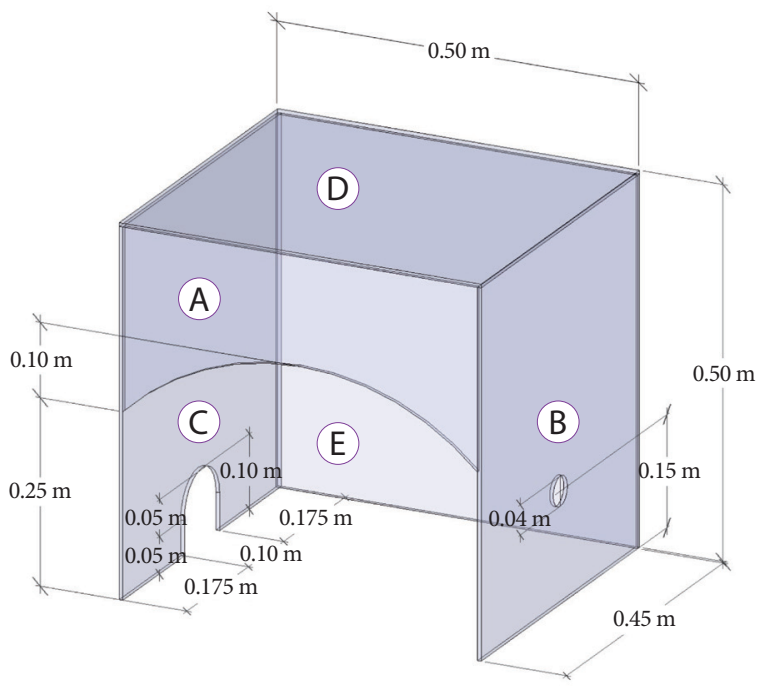

Fig. 1. A three-dimensional schematic of "Endoshield". (A) Wall A: Consists of a curved plastic board for covering the patient's head and shoulders. A transparent, thin, and soft plastic sheet (not shown in the Figure) was attached to the front of the wall to minimize droplet and aerosol distribution. B Wall B: It is a wall for the endoscope insertion, with a small round opening, $4 \mathrm{~cm}$ in diameter and $15 \mathrm{~cm}$ above the bottom of the wall. (C) Wall C: It is the wall for airway equipment, with a semicircular port $10 \mathrm{~cm}$ in diameter in the base of the wall. The design allows the respiratory support apparatus from the patient to pass through the port to connect with the anesthesiology machines. (D) and (E) Wall D and E: They are the top and back wall with no specific features.

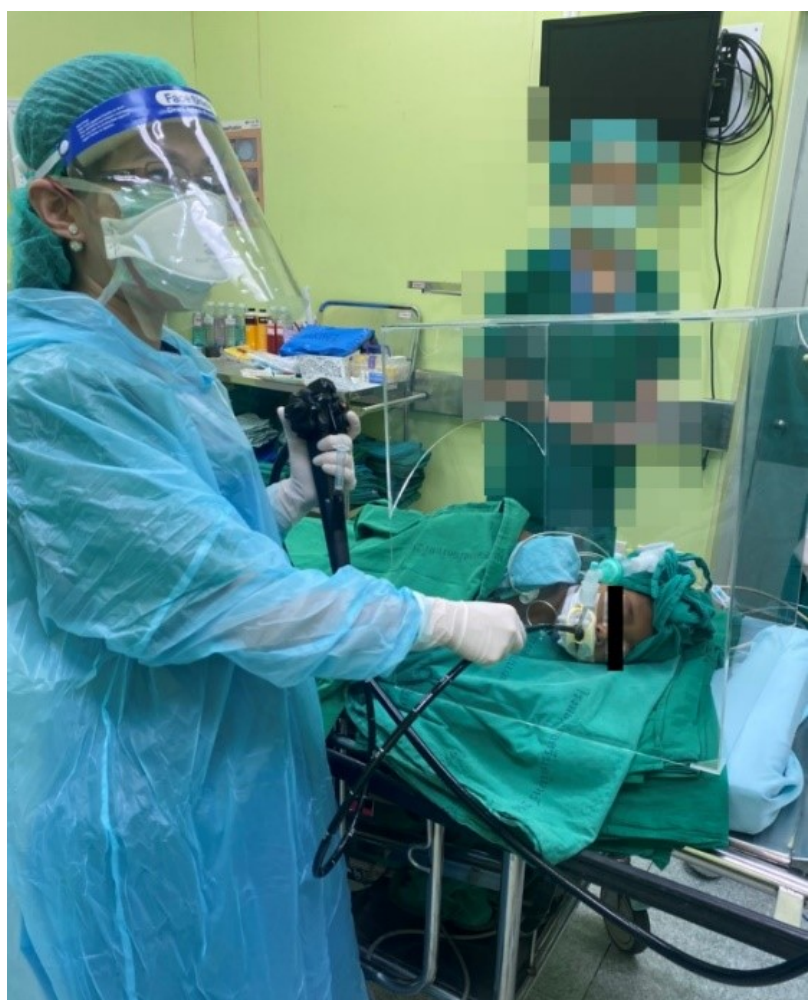

Fig. 2. Use of the "Endoshield" during a gastrointestinal endoscopy. After sedation was established, "Endoshield" was applied to the patient by placing it over their head and shoulders. The endoscope was inserted through a small round opening, $4 \mathrm{~cm}$ in diameter and $15 \mathrm{~cm}$ above the bottom of the wall. The respiratory support apparatus from the patient pass through the port to connect with the anesthesiology machines via a semicircular port $10 \mathrm{~cm}$ in diameter.

\section{RESULTS}

This research presents a descriptive case series of 12 children (66.67\% male) with a median age of 9 years (range, $2-11$ years) who underwent emergency or urgent endoscopy according to risk stratification ${ }^{8}$ between April and June 2020, which was during the COVID-19 outbreak. The vast majority of patients experienced life-threatening gastrointestinal bleeding requiring emergency endoscopy $(8 / 12,66.67 \%)$, while the rest of the patients underwent urgent endoscopy $(4 / 12,33.33 \%)$. All patients were screened, triaged, and stratified by symptom and exposure questionnaires for risk assessment before AGPs according to guidelines by international gastroenterology societies $^{6-9,21-23}$ and the Thai Association of Gastroenterology and Endoscopy (TAGE). ${ }^{9}$ All of the patients were classified into the low-risk group for COVID-19 infection; hence, they had not been tested for it. The "Endoshield" was applied and was found to be suitable for all patients' positions (left lateral position: $9 / 12,75 \%$ and supine position: $3 / 12,25 \%$ ). The median times for the endoscopy procedure in the left lateral position, supine position, and overall were $14.15 \mathrm{~min}$ (range, 10.50$15.49 \mathrm{~min}$ ), $19.59 \mathrm{~min}$ (range, 16.0-39.0 $\mathrm{min}$ ), and $15.39 \mathrm{~min}$ (range, 11.54-18.06 min), respectively. After completing each procedure, the patients and HCPs were followed up for symptoms via telemedicine on day 14, and none of them had any symptoms of concern (Table 2). 
Table 2. Patient Characteristics, Risk Stratification, Position, and Endoscopy Procedures

\begin{tabular}{|c|c|c|c|c|c|c|}
\hline Patient & $\begin{array}{l}\text { Age, yr } \\
\text { (gender) }\end{array}$ & Underlying disease & Presenting symptom & Risk stratification & AGPs & Position \\
\hline 1. & $0.3(\mathrm{M})$ & BA & $\begin{array}{l}\text { Life-threatening } \\
\text { GIB }\end{array}$ & Emergency & EVS & Left lateral \\
\hline 2. & $1(\mathrm{M})$ & BA & $\begin{array}{l}\text { Life-threatening } \\
\text { GIB }\end{array}$ & Emergency & EVS & Left lateral \\
\hline 3. & $3(\mathrm{M})$ & $\mathrm{CHF}$ & $\begin{array}{l}\text { Life-threatening } \\
\text { GIB }\end{array}$ & Emergency & EVL & Left lateral \\
\hline 4. & $5(\mathrm{M})$ & EHPVT & $\begin{array}{l}\text { Life-threatening } \\
\text { GIB }\end{array}$ & Emergency & EVL & Left lateral \\
\hline 5. & $9(\mathrm{M})$ & EHPVT & $\begin{array}{l}\text { Life-threatening } \\
\text { GIB }\end{array}$ & Emergency & EVL & Left lateral \\
\hline 6. & $9(\mathrm{M})$ & EHPVT & $\begin{array}{l}\text { Life-threatening } \\
\text { GIB }\end{array}$ & Emergency & EVL & Left lateral \\
\hline 7. & $15(\mathrm{M})$ & BA & $\begin{array}{l}\text { Life-threatening } \\
\text { GIB }\end{array}$ & Emergency & EVL & Left lateral \\
\hline 8. & $18(\mathrm{M})$ & $\begin{array}{c}\text { Lymphoma, CMV } \\
\text { esophagitis }\end{array}$ & $\begin{array}{l}\text { Life-threatening } \\
\text { GIB }\end{array}$ & Emergency & Endoscopic clips & Left lateral \\
\hline 9. & $1(\mathrm{~F})$ & None & Foreign body ingestion ${ }^{\text {a) }}$ & Urgent & Endoscopic removal & Left lateral \\
\hline 10. & $9(\mathrm{~F})$ & Medulloblastoma & Severe PEM $^{\text {b) }}$ & Urgent & PEG & Supine \\
\hline 11. & $10(\mathrm{~F})$ & MMA & Severe PEM $^{\mathrm{b})}$ & Urgent & PEG & Supine \\
\hline 12. & $12(\mathrm{~F})$ & Achalasia & Severe dysphagia & Urgent & $\begin{array}{c}\text { Endoscopic esophageal } \\
\text { dilatation }\end{array}$ & Supine \\
\hline
\end{tabular}

Ages are expressed as years.

AGPs, aerosol-generating procedures; BA, biliary atresia; CHF, congenital hepatic fibrosis; CMV, cytomegalovirus; EHPVT, extrahepatic portal vein thrombosis; EVL, endoscopic variceal ligation; EVS, endoscopic variceal sclerosis; GIB, gastrointestinal bleeding; MMA, methylmalonic academia; PEG, percutaneous endoscopic gastrostomy; PEM, protein energy malnutrition.

${ }^{a)}$ Foreign bodies have been classified by the NASPGHAN clinical report as urgent. ${ }^{23}$

${ }^{\text {b) }}$ rgent initial nutrition support. ${ }^{8}$

\section{DISCUSSION}

Recent knowledge shows that the major routes by which novel COVID-19 spreads are human-to-human transmission, including direct and indirect contact and droplets; airborne transmission is also possible, especially during aerosol generation, such as during GIEs. Due to the limitations of protective equipment, shortage of PPE, and lack of accurate and available COVID-19 tests in our country, the TAGE recommends obtaining the patient's information to determine the risk before performing AGPs. This includes fever (body temperature $>37.5^{\circ} \mathrm{C}$ ), travel history, occupational risk, contact history with confirmed infected patients, and close contact with un- familiar people. ${ }^{9}$ Nevertheless, in pediatric cases, screening by symptom-based questionnaires does not represent the actual status of COVID-19 infection because most children are asymptomatic or have only mild disease. ${ }^{10-16}$ All of the above limitations, especially the lack of protective supplies, must be overcome in crises. To prevent and minimize the spread of the disease, we used a simple, affordable, and reusable plastic box as a physical protective barrier for both patients and HCPs during AGPs, such as GIEs. The first published research in adults on physical barrier boxes involved transmission prevention during endotracheal intubation and airway procedures. Canelli et al. ${ }^{18}$ developed a transparent plastic box to protect HCPs performing endotracheal intubations. To achieve 
this, they put fluorescent dye in a balloon in a mannequin's pharynx and burst it to simulate a cough in humans; they then illuminated the area with ultraviolet light to detect the spread of the dye. They found no macroscopic dye outside the box. However, the use of a protective box also restricts the operator's movement. Bianco et $\mathrm{al}^{24}$ designed a box similar to that used by Canelli et $\mathrm{al}^{18}$, an "Aerosol Box" for endotracheal intubation purposes. They retrospectively analyzed six COVID-19-positive patients who underwent emergency surgical procedures wherein a box was used while the patient was intubated. Bianco et al. discussed that the box might have some limitations, such as box size and construction. ${ }^{24}$ For endoscopy purposes, Ljubicic et al. ${ }^{20}$ reported using a plexiglass barrier box to improve safety during endoscopic retrograde cholangiopancreatography. Nevertheless, they did not specifically test for efficacy, but the box was similar to a previous one used for intubation purposes. In one experimental study on the effectiveness of a box to minimize droplet and aerosol spreading during GIEs, Campos et al..$^{19}$ designed an acrylic box and tested its effectiveness by using fluorescent dyes and a similar method reported by Canelli et al. ${ }^{18}$ They proved not only its potential benefit in protecting HCPs from air droplets but also its feasibility and practicality during the procedure. In a recent publication, Sagami et al. ${ }^{25}$ created a barrier box to prevent droplets from spreading during endoscopy. Their methodology was identical to that of Canelli et al. ${ }^{18}$ and Campos et al., ${ }^{19}$ whereby they used fluorescent dyes to prove its efficacy. One real patient underwent an upper GIE without conscious sedation in the left lateral position. Neither discomfort nor any change in vital signs was detected. They concluded that the box could reduce the droplets spreading during GIE. To date, no previous studies have reported differences in adult and pediatric populations. In the pediatric setting, the patients have specific characteristics, such as the necessity of general anesthesia, being small in size, and having specific conditions that affect surgical positions. Our study revealed that the median time spent on endoscopy procedures with the "Endoshield" in the supine position was slightly longer than that in the left lateral position group. This was due to the more difficult endoscopy procedures such as PEG and endoscopic esophageal dilatation in the supine position group, as shown in Table 2. The present study revealed the feasibility of a pediatric size box, namely "Endoshield", as an adjunct tool with PPE for endoscopy. This is the first innovative device that is suitable for pediatric endoscopy. Even though our study did not prove the efficacy and safety of the box, we did prove that "Endoshield" is suitable for children of different sizes and different surgical positions and is convenient to use with anesthetic equipment. This box can be used as an additional physical protective de- vice during pediatric endoscopy procedures as well as in those undergoing endoscopy under deep sedation. The benefit of this box is that it not only minimizes disease transmission but also works suitably in the supine position of patients, a feature that no prior studies have mentioned. Further, large and well-designed studies specific to pediatric patients that focus on the efficacy of the box to prevent transmission are warranted.

\section{Conflicts of Interest}

The authors have no potential conflicts of interest.

$$
\begin{array}{r}
\text { Funding } \\
\text { None. }
\end{array}
$$

\section{Acknowledgments}

The authors are grateful to the patients and all staff of the Division of Gastroenterology and Hepatology, and the endoscopy nurses of the endoscopy unit, Faculty of Medicine, Khon Kaen University.

\section{Author Contributions}

Conceptualization: Busara Charoenwat, Suphasarang Sirirattanakul, Kangsadan Hangnak

Data curation: BC, SS, KH

Formal analysis: BC, Itsares Muikham

Investigation: $\mathrm{BC}$

Methodology: BC, KH, IM

Project administration: SS, KH

Validation: SS, $\mathrm{KH}$

Writing-original draft: BC

Writing-review\&editing: BC

\section{ORCID}

Busara Charoenwat:

Suphasarang Sirirattanakul:

Kangsadan Hangnak:

Itsares Muikham: https://orcid.org/0000-0003-4892-4993 https://orcid.org/0000-0003-4775-9754 https://orcid.org/0000-0001-7516-7305 https://orcid.org/0000-0002-3163-7229

\section{REFERENCES}

1. World Health Organization. Pneumonia of unknown cause - China [Internet]. Geneva: WHO; c2020 [updated 2020 Jan 5; cited 2020 Mar 21]. Available from: https://www.who.int/csr/don/05-january-2020pneumonia-of-unkown-cause-china/en/.

2. World Health Organization. WHO Director-General's opening remarks at the media briefing on COVID-19 - 11 March 2020 [Internet]. Geneva: WHO; c2020 [updated 2020 Mar 11; cited 2020 Mar 21]. Available from: https://www.who.int/director-general/speeches/detail/who-director-general-s-opening-remarks-at-the-media-briefing-on-covid-19--11-march-2020.

3. Bedford J, Enria D, Giesecke J, et al. COVID-19: towards controlling of a pandemic. Lancet 2020;395:1015-1018.

4. Zhu N, Zhang D, Wang W, et al. A novel coronavirus from patients with pneumonia in China, 2019. N Engl J Med 2020;382:727-733.

5. Wang C, Horby PW, Hayden FG, Gao GF. A novel coronavirus outbreak of global health concern. Lancet 2020;395:470-473. 
6. Chiu PWY, Ng SC, Inoue H, et al. Practice of endoscopy during COVID-19 pandemic: position statements of the Asian Pacific Society for Digestive Endoscopy (APSDE-COVID statements). Gut 2020;69:991-996.

7. Gralnek IM, Hassan C, Beilenhoff U, et al. ESGE and ESGENA position statement on gastrointestinal endoscopy and the COVID-19 pandemic. Endoscopy 2020;52:483-490.

8. Walsh CM, Fishman DS, Lerner DG. Pediatric endoscopy in the era of coronavirus disease 2019: a North American Society for Pediatric Gastroenterology, Hepatology, and Nutrition position paper. J Pediatr Gastroenterol Nutr 2020;70:741-750.

9. Kongkam P, Tiankanon K, Ratanalert S, et al. The practice of endoscopy during the COVID-19 pandemic: recommendations from the Thai Association for Gastrointestinal Endoscopy (TAGE) in collaboration with the Endoscopy Nurse Society (Thailand). Siriraj Medical Journal 2020;72:283-286.

10. Lu X, Zhang L, Du H, et al. SARS-CoV-2 infection in children. N Engl J Med 2020;382:1663-1665.

11. Kelvin AA, Halperin S. COVID-19 in children: the link in the transmission chain. Lancet Infect Dis 2020;20:633-634.

12. Dong Y, Mo X, Hu Y, et al. Epidemiology of COVID-19 among children in China. Pediatrics 2020;145:e20200702.

13. Su L, Ma X, Yu H, et al. The different clinical characteristics of corona virus disease cases between children and their families in China - the character of children with COVID-19. Emerg Microbes Infect 2020;9:707-713.

14. Qiu H, Wu J, Hong L, Luo Y, Song Q, Chen D. Clinical and epidemiological features of 36 children with coronavirus disease 2019 (COVID-19) in Zhejiang, China: an observational cohort study. Lancet Infect Dis 2020;20:689-696.
15. Cruz AT, Zeichner SL. COVID-19 in children: initial characterization of the pediatric disease. Pediatrics 2020;145:e20200834.

16. She J, Liu L, Liu W. COVID-19 epidemic: disease characteristics in children. J Med Virol 2020;92:747-754.

17. Begley JL, Lavery KE, Nickson CP, Brewster DJ. The aerosol box for intubation in coronavirus disease 2019 patients: an in-situ simulation crossover study. Anaesthesia 2020;75:1014-1021.

18. Canelli R, Connor CW, Gonzalez M, Nozari A, Ortega R. Barrier enclosure during endotracheal intubation. N Engl J Med 2020;382:1957-1958.

19. Campos S, Carreira C, Marques PP, Vieira A. Endoprotector: protective box for safe endoscopy use during COVID-19 outbreak. Endosc Int Open 2020;8:E817-E821.

20. Ljubicic N, Stojsavljevic-Shapeski S, Virovic-Jukic L, Nikolic M. Plexiglas barrier box to improve ERCP safety during the COVID-19 pandemic. Gastrointest Endosc 2020;92:428-429.

21. Lui RN, Wong SH, Sánchez-Luna SA, et al. Overview of guidance for endoscopy during the coronavirus disease 2019 pandemic. J Gastroenterol Hepatol 2020;35:749-759.

22. Edwards C, Penman ID, Coleman M. Gastrointestinal endoscopy during COVID-19: when less is more. Frontline Gastroenterol 2020;11:256-257.

23. Kramer RE, Lerner DG, Lin T, et al. Management of ingested foreign bodies in children: a clinical report of the NASPGHAN Endoscopy Committee. J Pediatr Gastroenterol Nutr 2015;60:562-574.

24. Bianco F, Incollingo P, Grossi U, Gallo G. Preventing transmission among operating room staff during COVID-19 pandemic: the role of the Aerosol Box and other personal protective equipment. Updates Surg 2020;72:907-910.

25. Sagami R, Nishikiori H, Sato T, Murakami K. Endoscopic shield: barrier enclosure during the endoscopy to prevent aerosol droplets during the COVID-19 pandemic. VideoGIE 2020;5:445-448. 